\title{
Use of AMMI and other stability statistics in the simultaneous selection of rice genotypes for yield and stability under direct-seeded conditions
}

\author{
Lotan Kumar Bose ${ }^{1 *}$, Nitiprasad Namdeorao Jambhulkar ${ }^{1}$, Kanailal Pande ${ }^{1}$, and Onkar Nath Singh ${ }^{1}$
}

Rice (Oryza sativa L.) is one of the most important cereal crops in the world. India is one of the largest rice-producing countries. Although more than 900 rice varieties have been released in India, many of them are no longer cultivated within a few years of release due to inconsistent performance in diverse environments; only a few varieties with stable performance continue to be under cultivation after 15 to $20 \mathrm{yr}$ of their release. Development and adaptability of rice cultivars in a wide range of target environments are the eventual goals of plant breeders. An attempt has been made to estimate the level of genotype-environment interaction (GEI) and eliminate as much as possible the unexplainable and extraneous variability contained in the data. Therefore, several statistical techniques have been used to describe GEI and measure genotype stability. Field experiments were conducted with 12 genotypes under direct-seeded conditions (irrigated and rainfed) for three consecutive years (2009 to 2012) in a randomized complete block design with three replicates. The GEI was analyzed using additive main effects and multiplicative interaction (AMMI). Results of AMMI analysis indicated that the first three AMMI (AMMI1 to AMMI3) were highly significant $(P<0.05)$. The partitioning of TSS (total sum of squares) exhibited that the genotype effect was a predominant source of variation followed by GEI and environment, which suggests the possible existence of different environment groups. The AMMI stability value discriminated genotypes 11 and 12 as stable genotypes based on the yield stability index (YSI) and sustainability index (SI).

Key words: AMMI model, AMMI stability value, direct-seeded rice, Oryza sativa, rank sum, yield stability index.

\section{INTRODUCTION}

Rice (Oryza sativa L.) is the staple food for a large proportion of the world's population (Zhang, 2007). India is the second largest rice-growing country in the world; however, its productivity per unit area is low. In India, rice is cultivated on 44.01 million hectares with a production of 105.31 million $t$ and productivity of 2.23 $\mathrm{t} \mathrm{ha}{ }^{-1}$. Although more than 900 rice varieties have been released in India, many of them were no longer cultivated within a few years due to inconsistent performance in diverse environments and only a few varieties with stable performance continue under cultivation after 15 to $20 \mathrm{yr}$ of their release. The rice production areas in the country are very diverse in hydrology and combined to other soil and climatic factors make a difference in rice yield (Singh et al., 1997). Analysis of genotype interaction

${ }^{1}$ Central Rice Research Institute, Cuttack (Orissa) 753006, India. *Corresponding author (lotanrice@gmail.com).

Received: 19 July 2013.

Accepted: 28 November 2013.

doi:10.4067/S0718-58392014000100001 with seasons and other agro-ecological conditions would help to get information on the adaptability and stability performance of genotypes. The genotype-environment interaction (GEI) reduces the association between phenotypic and genotypic values and leads to bias in the estimates of gene effects and combining ability for various characters that are sensitive to environmental fluctuations less amenable to selection (Farshadfar et al., 2000). Identification of superior genotypes through GEI became complicated for a range of environments to determine their true genetic potential (Yaghotipoor and Farshadfar, 2007). The importance of GEI in national cultivar evaluation and breeding programs has been demonstrated in almost all major crops (Najafian et al., 2010; Zali et al., 2011). Various statistical methods/ models (parametric and non-parametric), concepts, and definitions of stability have been described over the years by many researchers (Lin et al., 1986; Becker and Léon, 1988; Crossa et al., 1990; Lin and Binns, 1994; Hussein et al., 2000; Mohammadi and Amri, 2008; Mohammadi et al., 2010). The model used for GEI is similar to a static or biological concept of stability (Becker and Léon, 1988) and the parameters used in the study are the coefficient of determination $\left(R_{i}^{2}\right)$ (Pinthus, 1973), 
coefficient of variability $\left(C V_{i}\right)$ (Francis and Kannenberg, 1978), and the genotypic variances across environments $\left(S_{i}^{2}\right)$ (Roemer, 1917). Similarly, another model is the dynamic or agronomic concept of stability (Becker and Léon, 1988) where the parameters used are the regression coefficient $\left(b_{i}\right)$ (Finlay and Wilkinson, 1963) and Shukla's stability variance $\left(\sigma_{i}^{2}\right)$ (Shukla, 1972), the regression coefficient $\left(b_{i}\right)$, and deviation from regression $\left(S_{d_{i}}{ }^{2}\right)$ (Eberhart and Russell, 1966; Perkins and Jinks, 1968). The main problem with stability statistics is that a single model cannot provide an accurate picture because of the genotype's multivariate response to varying environments (Lin et al., 1986), whereas stability indices are usually univariate (Gauch, 1988; Crossa et al., 1990).

Stability methods have been used in both univariate and multivariate statistics (Lin et al., 1986). Among the multivariate methods, the additive main effects and multiplicative interaction (AMMI) analysis is widely used for GEI investigation. This method has been effective because it captures a large portion of the GEI sum of squares; it clearly separates main and interaction effects and often provides meaningful interpretation of data to support a breeding program such as genotype stability (Gauch and Zobel, 1989; 1996; 1997; Crossa et al., 1990). The AMMI model combines ANOVA for the genotype and environment main effects with principal components analysis of GEI (Zobel et al., 1988; Gauch and Zobel, 1996). Therefore, based on the AMMI model (IPCA1 and IPCA2) the AMMI stability value (ASV) has been used (Purchase et al., 2000). This ASV is comparable with the methods used by Shukla, Eberhart, and Russell for genotype stability (Purchase et al., 2000). The development and use of the yield-stability statistic (YSi) was also used to recommend varieties (Kang, 1993; Pazdernik et al., 1997). Kang (1993) proposed an improved superior stability index (I) that is free from all the aforesaid drawbacks (Rao and Prabhakaran, 2005). A new approach, known as genotype selection index (GSI), was used by taking into consideration the AMMI stability value and mean yield for yield stability (Farshadfar, 2008). The objectives of this study were (i) to identify rice genotypes that have both high mean yield and stable yield performance across different environments for a tropical country like India, and (ii) to study the relationships, similarities, and dissimilarities among yield-stability statistics.

\section{MATERIALS AND METHODS}

The experiment was conducted at the Central Rice Research Institute experimental farm, Cuttack $\left(20^{\circ} 26^{\prime} 35^{\prime}\right.$ ' $\mathrm{N}, 85^{\circ} 55^{\prime} 48^{\prime \prime} \mathrm{E} ; 24 \mathrm{~m}$ a.s.1.), India, during six consecutive wet-dry seasons from 2009 to 2012. Soil texture varied from loamy sand to clay loam. Seeds of 12 popular genotypes were direct-seeded in the experimental field during dry (irrigated) and wet season (rainfed) conditions
(Table 1). The experiment was laid out in a randomized complete block design with three replicates. Plant density was maintained at 33 plants $\mathrm{m}^{-2}$ with row and plant spacing of $20 \times 15 \mathrm{~cm}$. Fertilizer was applied at 80:40:40 of $\mathrm{N}: \mathrm{P}: \mathrm{K}$. The entire rate of $\mathrm{P}$ (DAP $87 \mathrm{~kg} \mathrm{ha}^{-1}$ ) and $\mathrm{K}$ (muriate of potash $67 \mathrm{~kg} \mathrm{ha}^{-1}$ ) along with $30 \mathrm{~kg} \mathrm{~N}$ (urea $32 \mathrm{~kg} \mathrm{ha}^{-1}$ ) were applied as the basal rate, while the rest of $50 \mathrm{~kg} \mathrm{~N}$ (urea $110 \mathrm{~kg} \mathrm{ha}^{-1}$ ) was applied in two split rates, the first one $21 \mathrm{~d}$ after germination and the other at the flowering initiation stage. Appropriate cultural practices such as weeding, intermittent irrigation, and need-based plant protection measures were undertaken to raise a healthy crop. At harvest, grain yields were adjusted at $12 \%$ moisture level and then converted to yield ha- ${ }^{-1}$. Data were analyzed with SAS 9.3 software (SAS Institute, Cary, North Carolina, USA).

\section{Statistical analysis}

Grain yield data were subjected to combined ANOVA and AMMI analysis. ANOVA was used to partition genotype deviations from the grand mean, environment deviations from the grand mean, and GE deviations from the grand mean. Subsequently, multiplication effect analysis (AMMI) was used to partition GE deviations into different interaction principal component axes (IPCA). The SAS 9.3 software was used for combined ANOVA and AMMI analysis.

\section{AMMI analysis}

The AMMI model was applied with additive effects for the 12 rice genotypes $(\mathrm{G})$ and six seasons of testing (Environments $=\mathrm{E}$ ), and multiplicative term for GEI. The AMMI analysis first fits additive effects for host genotypes and environments by the usual additive ANOVA procedure and then fits multiplicative effects for $\mathrm{G} \times \mathrm{E}$ (genotype $\times$ environment) by principal component analysis (PCA). The AMMI model is:

$$
Y_{i j}=\mu+g_{i}+e_{j}+\sum_{k=1}^{\mathrm{n}} \lambda_{k} a_{i k} \gamma_{j k}+\varepsilon_{i j}
$$

where $Y_{i j}$ is the yield of the $i^{\text {th }}$ genotype in the $j^{\text {th }}$ environment, $g_{i}$ is the $i^{\text {th }}$ genotype mean deviation, $e_{j}$ is the

Table 1. List of popular genotypes.

\begin{tabular}{|c|c|c|}
\hline $\mathrm{nr}$ & $\begin{array}{l}\text { Genotype } \\
\text { name }\end{array}$ & Reaction to biotic and abiotic stresses \\
\hline 1 & Heera & Irrigated \\
\hline 2 & Vandana & $\begin{array}{l}\text { Drought-tolerant, tolerant to Bl, Helminthosporium, and } \\
\text { BB }\end{array}$ \\
\hline 3 & KalingaIII & $\begin{array}{l}\text { Drought-tolerant, tolerant to B1, Helminthosporium, and } \\
\text { BB }\end{array}$ \\
\hline 4 & Satyabhama & Drought-tolerant with multiple resistance to $\mathrm{BB}$ and $\mathrm{Bl}$ \\
\hline 5 & Lalat & Irrigated with multiple resistance to $\mathrm{BB}$ and $\mathrm{B} 1$ \\
\hline 6 & Naveen & Irrigated with multiple resistance to $\mathrm{BB}$ and $\mathrm{Bl}$ \\
\hline 7 & Annada & Drought-tolerant \\
\hline 8 & Satabdi & Irrigated with long slender grain \\
\hline 9 & Tapaswini & Adapted to irrigated and rainfed lowland ecology \\
\hline 10 & IR 64 & Irrigated with long slender grain \\
\hline 11 & Satya Krishna & Double haploid adapted to irrigated ecology \\
\hline 12 & WITA 12 & $\begin{array}{l}\text { Introduced from West Africa. Adapted to favorable } \\
\text { irrigated and rainfed situation }\end{array}$ \\
\hline
\end{tabular}

BB: Bacterial blight, Bl: Blast. 
$j^{\text {th }}$ environment mean deviation, $\lambda_{k}$ is the square root of the eigen value of the PCA axis $k, \alpha_{i k}$ and $\gamma_{j k}$ are the principal component scores for PCA axis $k$ of the $i^{\text {th }}$ genotype and the $j^{\text {th }}$ environment, respectively, and $\varepsilon_{i j}$ is the residual.

The environment and genotype PCA scores are expressed as unit vector multiplied by the square root of $\lambda_{k}$, i.e., the environment PCA score $=\lambda_{k}{ }^{0.5} \gamma_{i k}$ and genotype PCA score $=\lambda_{k}{ }^{0.5} \alpha_{i k}$ (Zobel et al., 1988).

The AMMI stability index $\left(\mathrm{D}_{\mathrm{i}}\right)$, which is the distance of the interaction principal component (IPC) point with its origin in space, was estimated according to the formula suggested by Zhang et al. (1998):

$$
D_{i}=\sqrt{\sum_{s=1}^{c}} Y_{i s}^{2}
$$

where $c$ is the number of significant IPCs and $Y_{i s}{ }^{2}$ is the score/yield of the rice genotype $i$ in IPCs.

The AMMI analysis was conducted with the statistical software SAS 9.3. To assess fitting the AMMI model, predictive and post-predictive approaches offered by Zobel et al. (1988) were applied to the data. In addition to the above stability parameters, various yield-stability statistics were also calculated.

\section{AMMI stability value}

The AMMI stability value (ASV) described by Purchase et al. (2000) was calculated as follows:

$$
A S V=\sqrt{\left[\frac{I P C A 1_{\text {sumofsquare }}}{I P C A 2_{\text {sumofsquare }}}\left(I P C A 1_{\text {score }}\right)\right]^{2}+\left(I P C A 2_{\text {score }}\right)^{2}}
$$

where $S S_{I P C A I} / S S_{I P C A 2}$ is the weight given to the IPCA1 value by dividing the IPCA 1 sum of squares by the IPCA 2 sum of squares. The higher the IPCA score, either negative or positive, the more specifically adapted a genotype is to certain environments. Lower ASV scores indicate a more stable genotype across environments.

\section{Sustainability index}

The sustainability index (SI) was calculated by the following formula suggested by Babarmanzoor et al. (2009):

$$
S I=[(Y-\sigma n) / Y M] \times 100
$$

where $Y$ is the mean performance of a genotype, $\sigma n$ is the standard deviation, and $Y M$ is the best performance of a genotype in any year.

The SI values were classified arbitrarily into five groups, i.e., very low (up to $20 \%$ ), low (21\% to $40 \%$ ), moderate ( $41 \%$ to $60 \%$ ), high (61\% to $80 \%)$, and very high (above $80 \%$ ).

\section{Stability index}

The stability index $(I)$ was computed by non-parametric stability analysis (Bajpai and Prabhakaran, 2000) to identify stable and high-yielding genotypes (Rao et al., 2004):

$$
I=\left(\frac{\bar{y}_{i .}}{\bar{y}_{. .}}+\frac{1}{\sigma_{i}^{2}}\right) /\left[\frac{1}{n} \sum_{i}\left(\frac{1}{\sigma_{i}^{2}}\right)\right]
$$

where $\bar{y}_{i}$ is the mean performance of the $i^{\text {th }}$ genotype, $\bar{y}$. is the overall mean, $\sigma_{i}^{2}$ is Shukla's stability variance (Shukla, 1972) of the $i^{\text {th }}$ genotype, and $n$ is the number of environments.

\section{Yield stability index and rank sum}

The yield stability index (YSI) and rank sum (RS) were calculated as:

$$
\mathrm{YSI}=\mathrm{RASV}+\mathrm{RY}
$$

where RASV is the rank of the AMMI stability value and $\mathrm{RY}$ is the rank of the mean grain yield of genotypes (RY) across environments.

$\mathrm{RS}=$ Rank mean $(\mathrm{R})+$ Standard deviation of rank (SDR)

The RS incorporates both yield and yield stability in a single non-parametric index, while YSI incorporates both mean yield and stability in a single criterion. Low values of both parameters show desirable genotypes with high mean yield and stability.

The standard deviation of rank (SDR) was measured as:

$$
S_{i}^{2}=\frac{\sum_{j=i}^{\mathrm{m}}\left(R_{i j}-\bar{R}_{i}\right)^{2}}{l-1}
$$

where $R_{i j}$ is the rank of $X_{i j}$ in the $j^{\text {th }}$ environment, $\bar{R}_{i .}$ is the mean rank across all environments for the $i^{\text {th }}$ genotype, and $S D R=\left(S_{i}^{2}\right)^{0.5}$.

\section{RESULTS AND DISCUSSION}

\section{Yield adaptation across environments}

Combined ANOVA (Table 2) of 12 genotypes under irrigated and rainfed conditions and over the years resulted in highly significant differences $(\mathrm{P}<0.01)$. The significant GEIs (seasons and years) suggest that grain yield of genotypes varied across irrigated and rainfed conditions. Significant differences for genotypes, environments, and GEI indicated the effect of environments in GEI, genetic variability among entries, and the possibility of selecting stable genotypes. Chandra et al. (1974) reported that GEI with location is more important than GEI with year. Since GEI was significant, we therefore move further to estimate phenotypic stability (Farshadfar and Sutka, 2006). The mean grain yield of genotypes ranged from $5572 \mathrm{~kg} \mathrm{ha}^{-1}$ for genotype 11 to $3083 \mathrm{~kg} \mathrm{ha}^{-1}$ for genotype 1 . Genotypes of annual crops evaluated for grain yield on a multiseasonal and multi-year basis show that the selection or recommendation of materials is complicated by GEI.

Table 2. ANOVA for grain yield under different irrigated and rainfed conditions.

\begin{tabular}{lrc}
\hline Source of variation & df & F-values \\
\hline Year $(\mathrm{Y})$ & 2 & 1.370 \\
Genotype $(\mathrm{G})$ & 11 & $53.310^{*}$ \\
G $\times$ Y & 22 & $1.530^{*}$ \\
Error & 180 & 13.50 \\
CV, $\%$ & & \\
"Significant at 1\% probability level.
\end{tabular}


Coping with GEI genotype-year or genotype-season-year interaction effects is possible only by selecting for yield stability across environments (Annicchiarico, 1997). There are two possible strategies to develop genotypes with GEI. (i) The sub-division or stratification of a heterogeneous area into smaller, more homogeneous subregions and with breeding programs aimed at developing genotypes for specific sub-regions. However, even with this refinement, the level of interaction can remain high because the breeding area does not reduce the interaction of genotypes with location with years (Eberhart and Russell, 1966; Tai, 1979). (ii) The strategy to reduce GEI involves selecting genotypes with a better stability across a wide range of environments to better predict behavior (Yaghotipoor and Farshadfar, 2007). Therefore, an attempt has been made with this experiment to study the relationships, similarities, and dissimilarities of the yieldstability of univariate and multivariate statistics.

\section{AMMI analysis of GEI}

The AMMI is more appropriate in the initial statistical analysis of yield trials because it provides an analytical tool to diagnose other models, such as subcases, when these are better for particular data sets and also have a good chance of predicting new sites and new years, this is a real advance (Gauch, 1988). The advantages of the AMMI model or its variants are that they use overall fitting, impose no restrictions on the multiplicative terms, and result in a least squares fit (Freeman, 1990); within limits, any model may also be expected to fit data from which it was derived. The AMMI method is used for three main purposes. The first is that the model diagnoses other models; secondly, AMMI clarifies GEI and summarizes patterns and relationships of $\mathrm{G}$ and $\mathrm{E}$ (Zobel et al., 1988; Crossa et al., 1990), and the third use is the accuracy of yield estimates (Zobel et al., 1988; Crossa et al., 1990). The GEI was further partitioned by PCA (Table 3 and Figure 1). It is evident from Table 3 that using biplots in interactions was very limited where the first two PCA axes explain $71.34 \%$ of the total interaction. As a result, it was not possible to conclude on genotype stability based on these two axes. Accordingly, the index and stability values are calculated by retaining 3 PCA axes in the model (AMMI1 to AMMI3) (Rao and Prabhakaran, 2005). The results of AMMI analysis indicated that the first three AMMI (AMMI1 to AMMI3) were highly significant $(P<0.05)$ (Table 3). The partitioning of TSS indicated that the genotype effect was a predominant source of variation followed by the GE and environment effect. The genotype effect was approximately six times higher than GEI, which suggests the possible existence of different genotype groups (Mohammadi et al., 2011).

\section{IPCAs interaction (crossover and non-crossover interactions)}

Principal components analysis (PCA) is a multivariate
Table 3. AMMI analysis of grain yield in 12 rice genotypes under rainfed and irrigated conditions.

\begin{tabular}{lrlc}
\hline Source & df & MS & TSS explained \% \\
\hline Genotypes (G) & 11 & $6.825^{* *}$ & 84.37 \\
Environments (E) & 5 & $0.394 \mathrm{~ns}$ & 2.21 \\
G×E & 55 & $0.217^{* * *}$ & 13.41 \\
Model & 16 & $4.815^{* *}$ & 86.59 \\
AMMI1 & 15 & $1.150^{* *}$ & 48.18 \\
AMMI2 & 13 & $0.638^{* *}$ & 23.16 \\
AMMI3 & 11 & $0.544^{*}$ & 16.73 \\
AMMI4 & 9 & $0.427 \mathrm{~ns}$ & 10.74 \\
Error & 142 & & \\
\hline
\end{tabular}

${ }^{* *}$ Significant at $1 \%$ probability level.

* Significant at $5 \%$ probability level.

ns: Non significant; AMMI: additive main effect and multiplicative interaction, df: degrees of freedom, MS: mean sum of squares, TSS: total sum of squares.

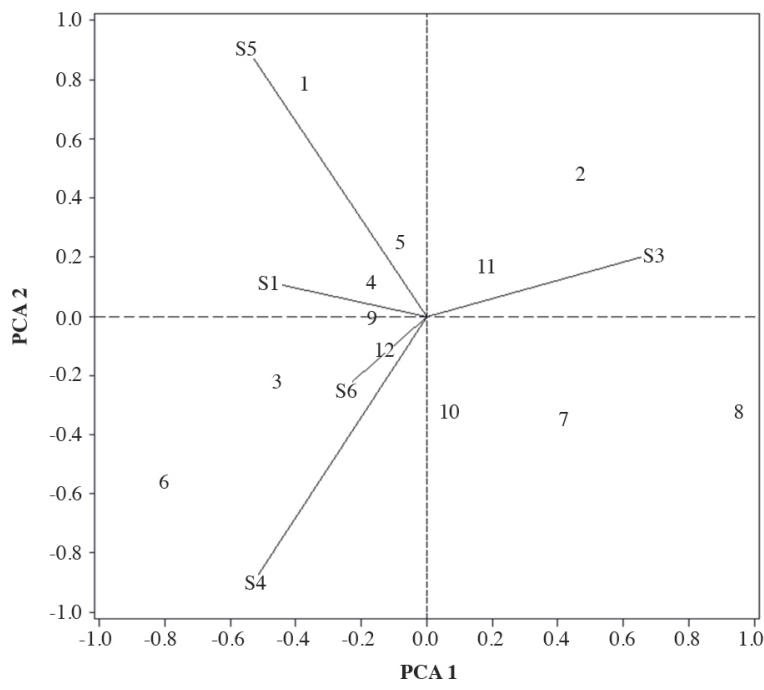

Figure 1. Biplot of 12 genotypes and six environments (rainfed and irrigated) for grain yield using genotype and environmental scores.

statistical method to identify data patterns as well as similarities and dissimilarities among variables based on ordination techniques of multivariate methods. The IPCA scores of genotype and environment had both positive and negative values (Table 4). Consequently, a genotype with a positive IPCA score in some environments must have negative interactions in other environments. Thus, these scores exhibited a disproportionate genotype response (Yan and Hunt, 2001; Mohammadi et al., 2007), which was the major source of variation for any crossover (qualitative) interaction. For convenience, this disproportionate genotype response is referred to as crossover GEI. On the other hand, same sign or near zero scores represent a non-crossover (quantitative) GEI or a proportionate genotype response (Mohammadi et al., 2007; Mohammadi and Amri, 2008; Farshadfar, 2008).

\section{AMMI stability value}

The AMMI model does not provide for a quantitative stability measure and such a measure is essential to quantify and rank genotypes in terms of yield stability (Gauch, 1992; Gauch and Zobel, 1996). Therefore, the 
Table 4. First and second IPCA, mean yield, and various yield-stability statistics under rainfed and irrigated conditions.

\begin{tabular}{|c|c|c|c|c|c|c|c|c|}
\hline Genotype & IPCA1 & IPCA2 & GY & ASVi & YSIi & SI (\%) & I & RS \\
\hline 1 & -0.375 & 0.798 & 3.133 & 1.116 & 22 & 60.229 & 0.136 & 13.828 \\
\hline 2 & 0.474 & 0.492 & 3.678 & 1.102 & 18 & 76.863 & 0.220 & 14.099 \\
\hline 3 & -0.452 & -0.221 & 3.500 & 0.966 & 19 & 75.006 & 0.298 & 12.828 \\
\hline 4 & -0.172 & 0.118 & 3.572 & 0.376 & 15 & 80.198 & 1.997 & 12.239 \\
\hline 5 & -0.078 & 0.251 & 3.878 & 0.299 & 10 & 84.889 & 1.408 & 10.365 \\
\hline 6 & -0.788 & -0.551 & 4.372 & 1.728 & 18 & 72.758 & 0.112 & 10.936 \\
\hline 7 & 0.417 & -0.341 & 5.206 & 0.931 & 11 & 81.312 & 0.195 & 6.447 \\
\hline 8 & 0.955 & -0.317 & 4.794 & 2.011 & 18 & 74.318 & 0.119 & 11.013 \\
\hline 9 & -0.159 & 0.016 & 4.933 & 0.331 & 8 & 84.825 & 0.478 & 7.000 \\
\hline 10 & 0.089 & -0.311 & 5.633 & 0.362 & 7 & 85.265 & 0.480 & 5.781 \\
\hline 11 & 0.202 & 0.171 & 6.356 & 0.454 & 7 & 92.494 & 0.387 & 3.159 \\
\hline 12 & -0.114 & -0.106 & 6.017 & 0.260 & 3 & 90.542 & 0.669 & 3.850 \\
\hline
\end{tabular}

IPCA: Interaction principal component axes, GY: grain yield, ASVi: AMMI stability value, AMMI: additive main effects and multiplicative interaction, YSIi: yield stability index, SI: sustainability index, I: stability index, RS: rank sum.

AMMI stability value (ASV) was proposed by Purchase et al. (2000) to quantify and rank genotypes according to their yield stability. The ASV is the distance from zero in a two-dimensional scattergram of IPCA1 (interaction principal component analysis axis 1) scores against IPCA2 scores. Since the IPCA1 score contributes more to GE sum of squares (Table 2), it has to be weighted by the proportional difference between IPCA1 and IPCA2 scores to compensate for the relative contribution of IPCA1 and IPCA2 to the total GE sum of squares. The distance from zero is then determined using the Pythagorean Theorem (Purchase et al., 2000). In the ASV method, a genotype with the lowest ASV score is the most stable; accordingly, genotype 12 was the most stable followed by genotype 5 .

\section{Yield stability index}

Another approach, known as the yield stability index (YSI), is calculated by ranking the mean grain yield of genotypes (RY) across environments and rank of AMMI stability value (RASV). The YSI incorporates both mean yield and stability in a single criterion as follows:

$$
\text { YSI = RASV + RY }
$$

A low value of this parameter shows stable genotypes with a high mean yield. By using these measures, suitable rice varieties can be identified for varying existing environmental conditions. Stability per se should however not be the only selection parameter because the most stable genotypes would not necessarily give the best yield performance (Mohammadi et al., 2007; Mohammadi and Amri, 2008); hence, there is a need for approaches that incorporate both mean yield and stability in a single index and that is why various authors have introduced different selection criteria for simultaneous selection of yield and stability (Eskridge, 1990; Kang, 1993; Dashiell et al., 1994; Bajpai and Prabhakaran, 2000; Rao and Prabhakaran, 2005; Farshadfar, 2008; Babarmanzoor et al., 2009). In this regard, since ASV takes into account both IPCA1 and IPCA2, most of the variation in the GE interaction is justified; therefore, the rank of ASV and yield mean is such that the lowest ASV is rank one, while the highest yield mean is rank one and the ranks are then summed in a single simultaneous selection index of yield and yield stability called the yield stability index (YSI).
The lowest YSI is considered as the most stable with high grain yield. Based on YSI, the most stable genotypes with high grain yield are genotypes 11 and 12 .

\section{Sustainability index}

Various authors used the sustainability index (SI) to select stable genotypes (Singh and Agarwal, 2003; Gangwar et al., 2004; Tuteja, 2006). The values of SI were divided arbitrarily into five groups, i.e., very low (up to $20 \%$ ), low $(21 \%$ to $40 \%)$, moderate ( $41 \%$ to $60 \%)$, high $(61 \%$ to $80 \%$ ), and very high (above $80 \%$ ) (Babarmanzoor et al., 2009). The SI of each genotype is shown in Table 4. A very high SI (\%) was estimated in the case of genotype 11 $(85.33 \%)$, while genotypes 12,10 , and 9 showed high SIs ( $80 \%$ to $84 \%$ ). These results prove that SI also provides a suitable stability index to discriminate stable genotypes with high grain yield.

\section{Stability index}

The rank sum method has an inherent weakness since it weighs heavily in the direction of yield performance and is also arbitrary in scoring. Therefore, this method is not suitable for drawing general conclusions. Keeping in mind these points, Bajpai and Prabhakaran (2000) proposed a new index that is free from all the aforesaid drawbacks. The basic element in the construction of this proposed index is that the performance levels of genotypes and their stability are quantified by expressing individual achievements related to the mean performance in the set of evaluated genotypes. The proposed index has a builtin integration of both stability and mean performance. According to Bajpai and Prabhakaran (2000), genotypes were ranked based on the stability index (I). Ranks were assigned in increasing order to the genotypes whose I varied in decreasing order, i.e., the genotype with the highest I received the first rank and the one with the lowest I received the $12^{\text {th }}$ rank in the present study, which included 12 genotypes. Results (Table 4) indicated that the ranking of genotypes was generally more or less similar based on I. However, the same was not true with respect to mean performance. Furthermore, genotype performance (genotypes 4 and 5) was not stable across rainfed and irrigated conditions as indicated by high levels of I for 
grain yield (Rao et al., 2004). Rank sum (RS) showed genotype $11(\mathrm{RS}=3.159)$ followed by genotype $12(\mathrm{RS}=$ 3.850 ) as the most stable genotypes with high grain yield. Both YSI and RS showed genotypes 11 and 12 as stable with high grain yield.

\section{Principal components}

To better understand the relationships, similarities, and dissimilarities among yield-stability statistics, we used principal component analysis (PCA) based on the rank correlation matrix. The relationships among different stability parameters are graphically displayed in a biplot of PCA1 and PCA2 (Figure 2). The PCA1 and PCA2 axes, which justify $94.15 \%$ of the total variation, mainly show the statistics in different groups. Stability measures included mean GY and RS in group $1(\mathrm{G} 1)$. The SI and YSI were in the same group (G2), whereas I and ASV were separated in another group (G3) (Figure 2). The statistics for G2 (YSI and SI) showed genotypes 11 and 12 as the most stable genotypes with high grain yield. The advantage of YSI over SI is a genotype's multivariate response to varying environments. YSI is based on a multivariate AMMI stability value, whereas SI is a univariate statistic.

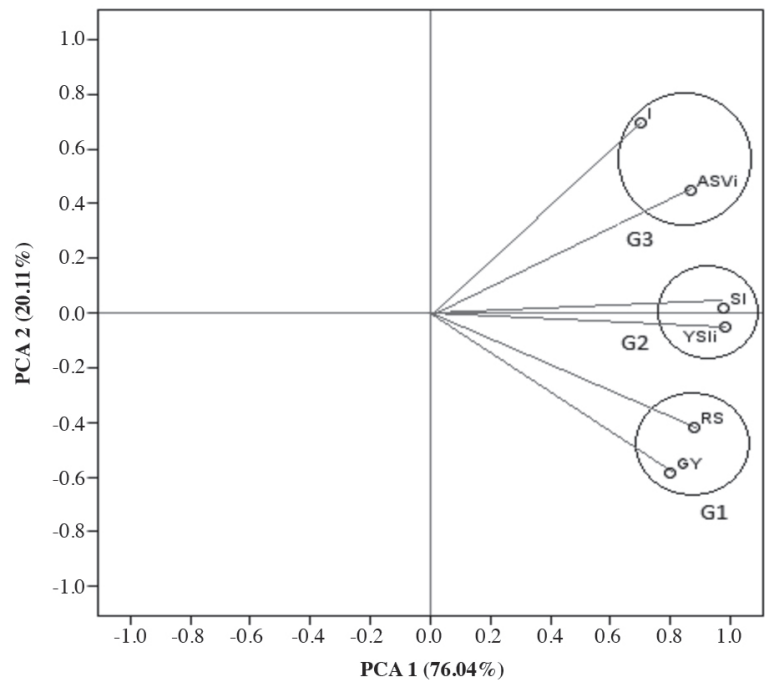

PCA: Principal component axes, GY: grain yield, ASVi: AMMI stability value, AMMI: additive main effects and multiplicative interactive, YSIi: yield stability index, SI: sustainability index, I: stability index, RS: rank sum.

Figure 2. Biplot of yield stability statistical models in rice genotypes under rainfed and irrigated conditions.

\section{CONCLUSIONS}

The genotype $\mathrm{x}$ environment interaction (GEI) has been an important and challenging issue among plant breeders, geneticists, and agronomists engaged in performance testing. The GEI reduces association between phenotypic and genotypic values and leads to bias in the estimates of gene effects and combining ability for various characters that are sensitive to environmental fluctuations. Such traits are less amenable to selection. Both yield and stability of performance should be considered simultaneously to reduce the effect of GEI and useful for selecting genotypes in a more precise and refined way. The results of this investigation proved that the stability index (SI) and yield stability index (YSI) are suitable stability indices in discriminating stable genotypes with high grain yield. Genotypes 11 and 12 were identified as being the most stable with high grain yield based on YSI and SI stability indices. The advantage of YSI over SI is that the genotype response to varying environments is multivariate (based on AMMI stability value), whereas SI is a univariate statistic.

\section{LITERATURE CITED}

Annicchiarico, P. 1997. Additive main effects and multiplicative interaction (AMMI) analysis of genotype location interaction in variety trials repeated over years. Theoretical and Applied Genetics 94:1072-1077.

Babarmanzoor, A., M.S. Tariq, A. Ghulam, and A. Muhammad. 2009. Genotype $\times$ environment interaction for seed yield in Kabuli Chickpea (Cicer arietinum L.) genotypes developed through mutation breeding. Pakistan Journal of Botany 41:1883-1890.

Bajpai, P.K., and V.T. Prabhakaran. 2000. A new procedure of simultaneous selection for high yielding and stable crop genotypes. Indian Journal of Genetics and Plant Breeding 60:141-146.

Becker, H.C., and J. Léon. 1988. Stability analysis in plant breeding. Plant Breeding 101:1-23.

Chandra, S., M.S. Sohoo, and K.P. Singh. 1974. Genotypeenvironment interaction for yield in ram. Journal of Research 8:165-168.

Crossa, J., H.G. Gauch, and R.W. Zobel. 1990. Additive main effects and multiplicative interactions analysis of two international maize cultivar trials. Crop Science 30:493-500.

Dashiell, K.E., O.J. Ariyo, and L. Bello. 1994. Genotype x environment interaction and simultaneous selection for high yield and stability in soybeans (Glycine max (L.) Merr.) Annals of Applied Biology 124:133-139.

Eberhart, S.A., and W.A. Russell. 1966. Stability parameters for comparing varieties. Crop Science 6:36-40.

Eskridge, K.M. 1990. Selection of stable cultivars using a safety-first rule. Crop Science 30:369-374.

Farshadfar, E. 2008. Incorporation of AMMI stability value and grain yield in a single non-parametric index (GSI) in bread wheat. Pakistan Journal of Biological Science 11:1791-1796.

Farshadfar, E., M. Farshadfar, and J. Sutka. 2000. Combining ability analysis of drought tolerance in wheat over different water regimes. Acta Agronomica Hungarica 48:353-361.

Farshadfar, E., and J. Sutka. 2006. Biplot analysis of genotypeenvironment interaction in durum wheat using the AMMI model. Acta Agronomica Hungarica 54:459-467.

Finlay, K.W., and G.N. Wilkinson. 1963. The analysis of adaptation in a plant-breeding programme. Australian Journal of Agricultural Research 14:742-754.

Francis, T.R., and L.W. Kannenberg. 1978. Yield stability studies in short-season maize. 1. A descriptive method for grouping genotypes. Canadian Journal of Plant Science 58:1029-1034.

Freeman, G.H. 1990. Modern statistical methods for analyzing genotype-environment interactions. p. 118-125. In M.S. Kang (ed.) Genotype $\times$ environment interaction and plant breeding. Louisiana State University Agricultural Center, Baton Rouge, Louisiana, USA.

Gauch, H.G. 1988. Model selection and validation for yield trials with interaction. Biometrics 44:705-715. 
Gauch, H.G. 1992. Statistical analysis of regional yield trials: AMMI analysis of factorial designs. Elsevier, Amsterdam, The Netherlands.

Gauch, H.G., and R.W. Zobel. 1989. Accuracy and selection success in yield trials analysis. Theoretical and Applied Analysis 77:443481.

Gauch, H.G., and R.W. Zobel. 1996. AMMI analyses of yield trials. p. 85-122. In Kang, M.S., and H.G. Gauch (eds.) Genotype by environment interaction. CRC, Boca Raton, Florida, USA.

Gauch, H.G., and R.W. Zobel. 1997. Identifying mega-environments and targeting genotypes. Crop Science 37:311-326.

Gangwar, B., V. Katyal, and K.V. Anand. 2004. Stability and efficiency of cropping systems in Chatisgarh and Madhya Pradesh. Indian Journal of Agricultural Science 74:521-528.

Hussein, M.A., A. Bjornstad, and A.H. Aastveit. 2000. SASG 3 ESTAB: A SAS program for computing genotype 3 environment stability statistics. Agronomy Journal 92:454-459.

Kang, M.S. 1993. Simultaneous selection for yield and stability in crop performance trials: Consequences for growers. Agronomy Journal 85:754-757.

Lin, C.S., and M.R. Binns. 1994. Concepts and methods for analyzing regional trial data for cultivar and location selection. Plant Breeding Review 12:271-297.

Lin, C.S., M.R. Binns, and L.P. Lefkovitch. 1986. Stability analysis: Where do we stand? Crop Science 26:894-900.

Mohammadi, R., A. Abdulahi, R. Haghparast, and M. Armion. 2007. Interpreting genotype- environment interactions for durum wheat grain yields using non-parametric methods. Euphytica 157:239251.

Mohammadi, R., and A. Amri. 2008. Comparison of parametric and non-parametric methods for selecting stable and adapted durum wheat genotypes in variable environments. Euphytica 159:419432.

Mohammadi, R., S.E. Davood, A. Mohammad, and A. Ahmed. 2011. Evaluation of durum wheat experimental lines under different climate and water regime conditions of Iran. Crop and Pasture Science 62:137-151.

Mohammadi, R., R.M. Mozaffar, A. Yousef, A. Mostafa, and A. Amri. 2010. Relationships of phenotypic stability measures for genotypes of three cereal crops. Canadian Journal Plant Science 90:819-830.

Najafian, G., A.K. Kaffashi, and A. Jafar-Nezhad. 2010. Analysis of grain yield stability in hexaploid wheat genotypes grown in temperate regions of Iran using additive main effects and multiplicative interaction. Journal of Agricultural Science and Technology 12:213-222.

Pazdernik, D.L., L.L. Hardman, and J.H. Orf. 1997. Agronomic performance of soybean varieties grown in three maturity zones of Minnesota. Journal of Production Agriculture 10:425-430.
Perkins, J.M., and J.L. Jinks. 1968. Environmental and genotype environmental components of variability. III. Multiple lines and crosses. Heredity 23:339-356.

Pinthus, M.J. 1973. Estimate of genotypic value: A proposed method. Euphytica 22:121-123.

Purchase, J.L., H. Hatting, and C.S. van Deventer. 2000. Genotype $x$ environment interaction of winter wheat (Triticum aestivum L.) in South Africa: П. Stability analysis of yield performance. South African Journal of Plant and Soil 17:101-107.

Rao, M., R.G. Lakshmikantha, R.S. Kulkarni, S.S. Lalitha Reddy, and S. Ramesh. 2004. Stability analysis of sunflower hybrids through non-parametric model. Helia 27:59-66.

Rao,A.R., and V.T. Prabhakaran. 2005. Use of AMMI in simultaneous selection of genotypes for yield and stability. Journal of the Indian Society of Agricultural Statistics 59:76-82.

Roemer, J. 1917. Sinde die ertagdreichen Sorten ertagissicherer? DLG-Mitteilungen 32:87-89.

Shukla, G.K. 1972. Some statistical aspects of partitioning genotypeenvironmental components of variability. Heredity 29:237-245.

Singh, P., and D.K. Agarwal. 2003. Sustainability index as an aid for determining the genotypic stability in diploid cotton (Gossypium arboreum). Journal of Cotton Research 17:90-92.

Singh, B.N., S. Fagade, M.N. Ukwungwu, C. Williams, S.S. Jagtap, O. Oladimeji, et al. 1997. Rice growing environment and biophysical constraint in rice agroecological Zones of Nigeria. Meteorology Journal 2:35-44.

Tai, G.C.C. 1979. Analysis of genotype-environment interaction of potato yield. Crop Science 19:434-438.

Tuteja, O.P. 2006. Comparative studies on stability parameters and sustainability index for selecting stable genotypes in upland cotton (Gossypium hirsutum L.) Indian Journal of Genetics and Plant Breeding 66:221-224.

Yaghotipoor, A., and E. Farshadfar. 2007. Non-parametric estimation and component analysis of phenotypic stability in chickpea (Cicer arietinum L.) Pakistan Journal of Biological Science 10:26462652.

Yan, W., and L.A. Hunt. 2001. Interpretation of genotype environment interaction for winter wheat yield in Ontario. Crop Science 41:19-25

Zali, H., E. Farshadfar, and S.H. Sabaghpour. 2011. Non-parametric analysis of phenotypic stability in chickpea (Cicer arietinum L.) genotypes in Iran. Crop Breeding Journal 1:89-100.

Zhang, Q. 2007. Strategies for developing green super rice. Proceeding of the National Academy of Sciences USA 104:1640216409.

Zhang, Z., C. Lu, and Z.H. Xiang. 1998. Analysis of variety stability based on AMMI model. Acta Agronomica Sinica 24:304-309.

Zobel, R.W., M.J. Wright, and H.G. Jr. Gauch. 1988. Statistical analysis of yield trial. Agronomy Journal 80:388-393. 